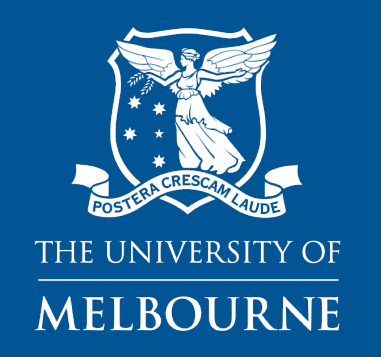

Faculty of Arts

Asia Institute

\title{
Draft Report on Tibet's Linguistic Minorities
}

\section{Dr. Gerald Roche}

g.roche@unimelb.edu.au

@GJosephRoche

21st February 2018 


\section{Contents}

0. Executive Summary 3

1. Introduction 4

2. Language Vitality 4

3. Language Transmission 6

4. Language Promotion $\quad 7$

5. Language Use in Different Areas of Life 8

6. Language Attitudes and Beliefs

7. Appendix One: The Languages 13

8. Appendix Two: Participants 15

9. Appendix Three: Defining Vitality Status 16

10. Appendix Four: Mapping Language Shift 17 


\section{Executive Summary}

This draft report provides new insights into the situation of the non-Tibetan languages spoken by Tibetans in the People's Republic of China.

Key findings are as follows:

Of the 20 languages surveyed, all are endangered (p4-5).

Experts believe that most of these languages will no longer be spoken by 2100 (p5).

Families are increasingly transmitting Chinese rather than their heritage language (p6).

All these languages are excluded from major social institutions such as media and education (p8-9).

Whilst Chinese dominates most social institutions, Tibetan dominates in religion (p8-10).

Speakers of minority languages typically face relatively mild levels of discrimination ( $\mathrm{p} 11)$.

Speakers of minority languages do not associate their language with their Tibetan identity (p12).

There appears to be a significant geographical basis to whether populations are shifting towards

Tibetan or Chinese ( $\mathrm{p} 17)$.

Funding for this research was provided by the Australian Research Council through a Discovery Early Career Research Award (DE150100388, 2015-2018). 


\section{Introduction}

This draft report is based on a preliminary analysis of the results of the 'Survey of Tibet's Minority Languages' conducted by Dr. Gerald Roche at the Asia Institute, University of Melbourne. The survey aimed to assess the vitality of approximately 30 languages spoken by Tibetans in China. 'Vitality' can be roughly defined as an indicator of a language's chances of being sustained in the future - if vitality is low, the language is less likely to be spoken in the future, if the vitality is high, it probably will.

Data were collected on 20 languages (see Appendix 1 for further information). This data consisted of expert testimony from linguists and anthropologists who are intimately familiar with the demographic, social, political, cultural contexts in which the languages are spoken (see Appendix 2 for details). Questions consisted of multiple choice and Likert scale questions; opportunity for open comment was also provided.

Where applicable, the caption above each graph shows the question that respondents were asked to answer. Unless otherwise stated, values shown indicate the number of languages. The information below each chart highlights key findings. This preliminary analysis of the data is being made available to help raise awareness of the situation faced by these languages; a more rigorous analysis will follow in subsequent publications.

\section{Language Vitality}

Figure 1. Response to the question, "How would you rate the vitality of this language?" (see Appendix 3 for details).

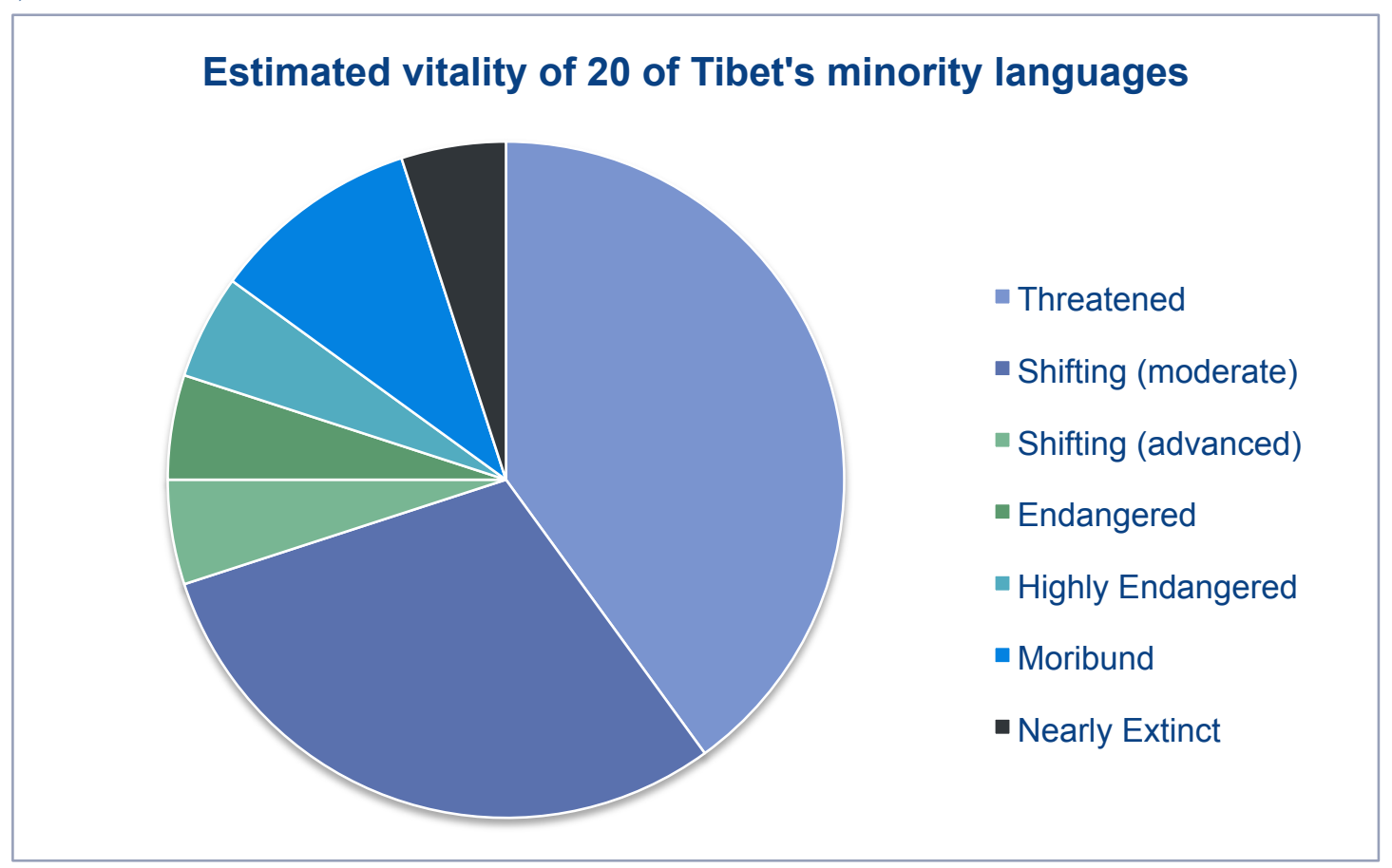

None of the 20 languages are stable - all of them have a decreasing number of speakers. 
Figure 2. The vitality of individual languages.

\begin{tabular}{|l|l|}
\hline Vitality & Languages \\
\hline Threatened & Namuyi; Baima; rTa’u; Geshiza; Situ Rgyalrong; Minyak; Shixing \\
\hline Shifting (moderate) & Lizu; Prinmi; Manegacha; Khroskyabs; nDrapa; Heishui Rma \\
\hline Shifting (advanced) & Zbu \\
\hline Endangered & Choyo \\
\hline Highly endangered & Gochang \\
\hline Moribund & Lhagang Choyu; Henan Oirat \\
\hline Nearly extinct & Tosu (Duoxu) \\
\hline
\end{tabular}

Most languages are either threatened or shifting (moderate).

Figure 3. Responses to the question, "Assuming that present social, political, and economic conditions prevail, is this language likely to be spoken in 2100 ?"

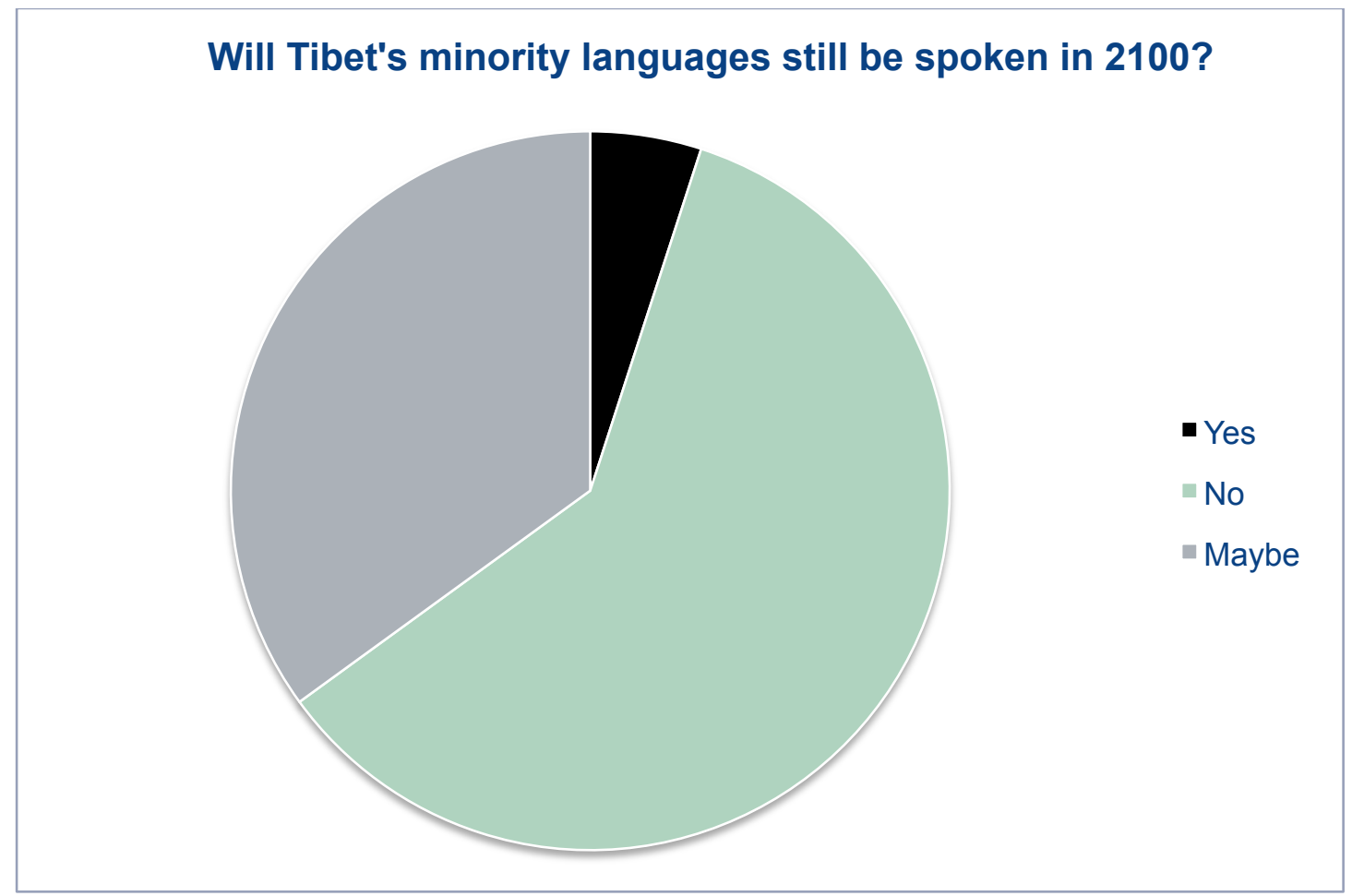

The experts' responses suggest that if current conditions continue, most (85\%) of the languages will no longer be spoken at the end of this century; there was only one positive answer to this question - for the Prinmi language. 


\section{Language Transmission}

Languages disappear when transmission ceases - when the language is no longer passed from one generation to the next.

Figure 4. Responses to the question, "Approximately what per cent of families are still transmitting the language?"

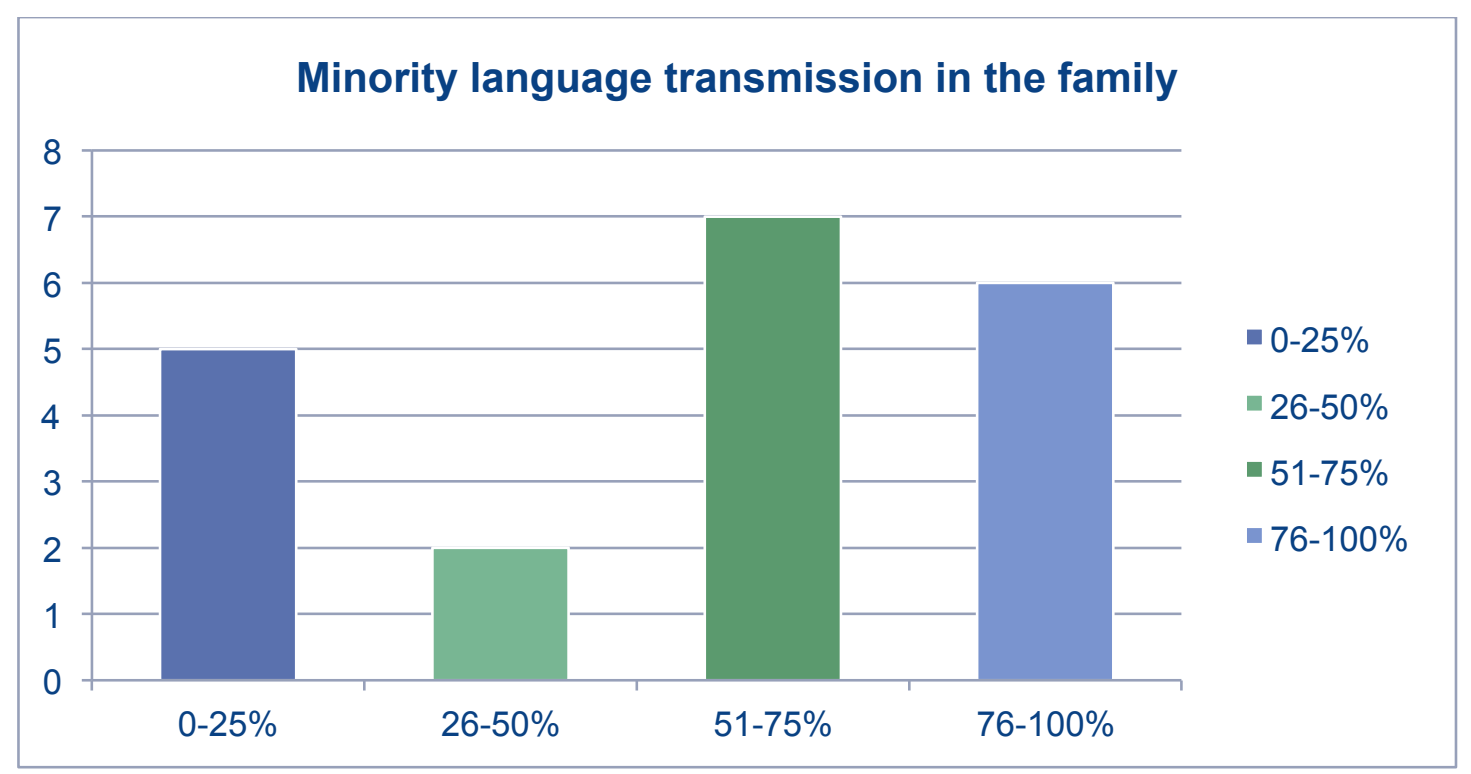

For 7 out of the 20 languages, less than half of families are transmitting the language.

Figure 5. Responses to the question, "If children do not learn the language, what language do they learn?" (see Appendix 4 for a map of language shift).

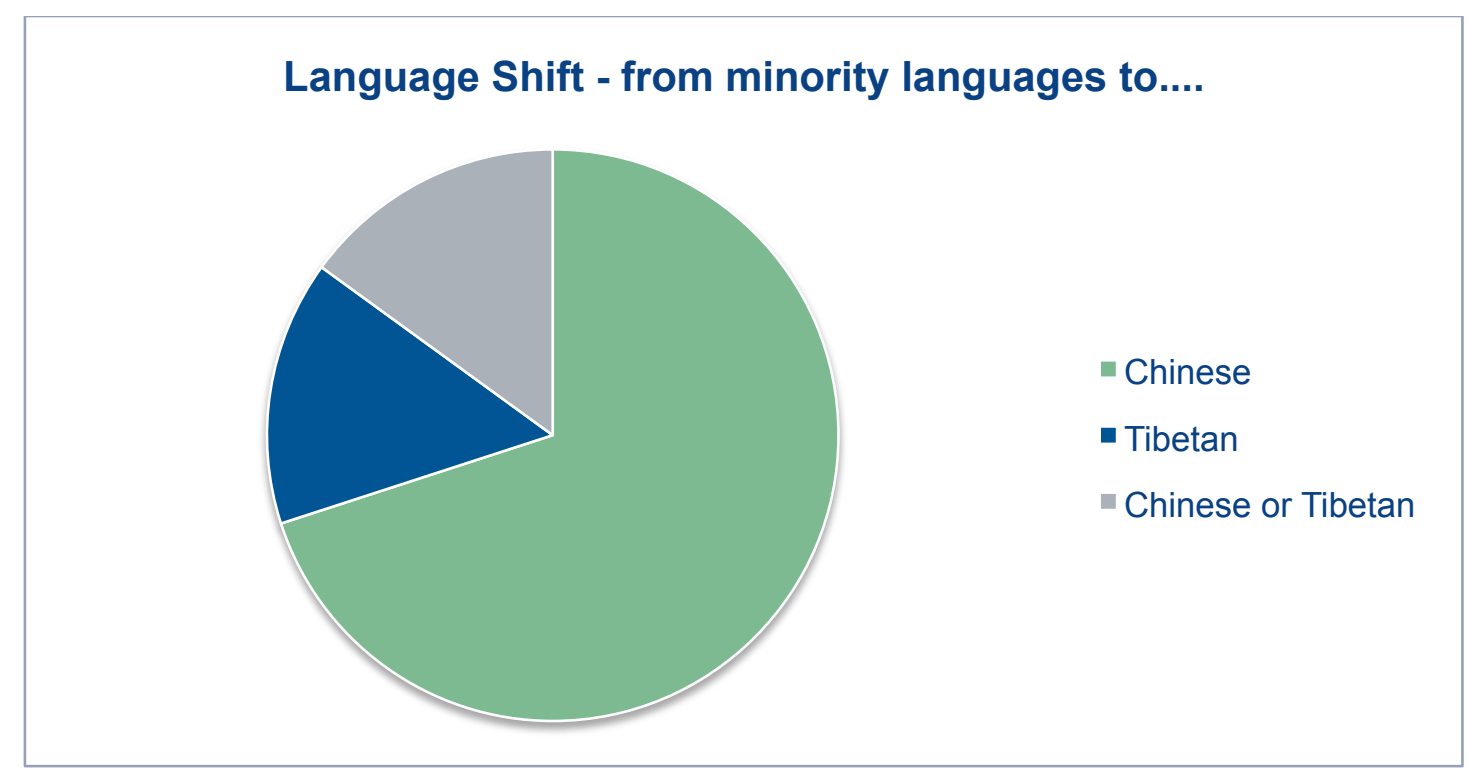

If children do not acquire their heritage language from their parents, in most cases (14/20), they learn Chinese, but some learn Tibetan. 


\section{Language Promotion}

Language shift is influenced by language promotion - emphasis by powerful political and social actors on the importance of speaking a particular language, and the commitment of material and moral resources to that language. So, which languages are publicly promoted amongst speakers of Tibet's minority languages?

Figure 6. Responses to the question, "Generally speaking, how strongly are these languages promoted?" $0=$ no promotion; $1=$ very weak promotion; $2=$ weak promotion; $3=$ neither weak not strong promotion; $4=$ strong promotion; $5=$ very strong promotion.

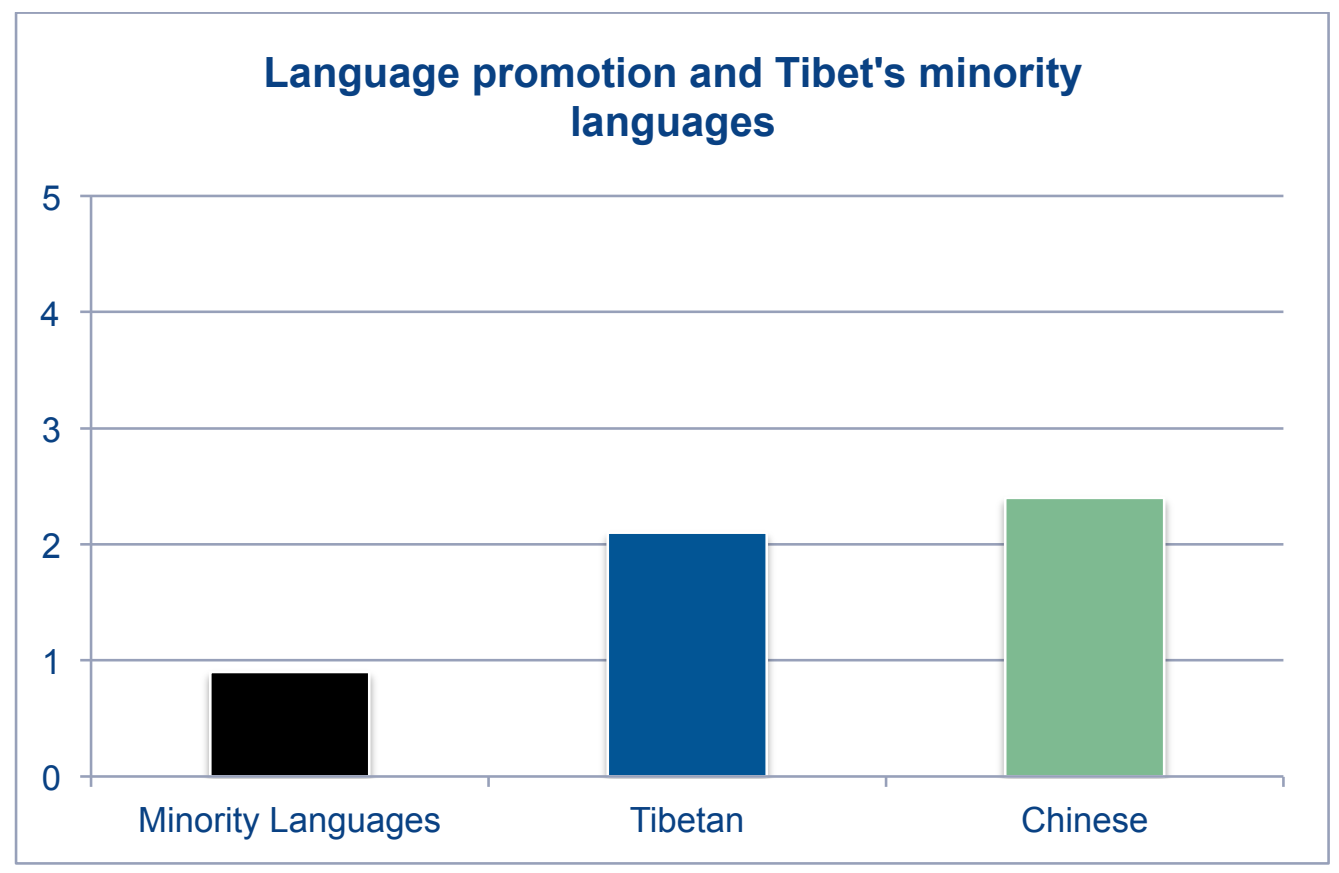

Promotion of minority languages is much weaker than promotion of Tibetan and Chinese. There is not a big difference between how strongly Tibetan and Chinese are promoted. 


\section{Language Use in Different Areas of Life}

This section explores how different language are used and promoted in different areas of life.

Figure 7. Response to the question, "How prominently are various languages displayed in urban environments?" $0=$ no signs; $1=$ a few signs; $2=$ some signs; $3=$ many signs; $4=$ =all signs.

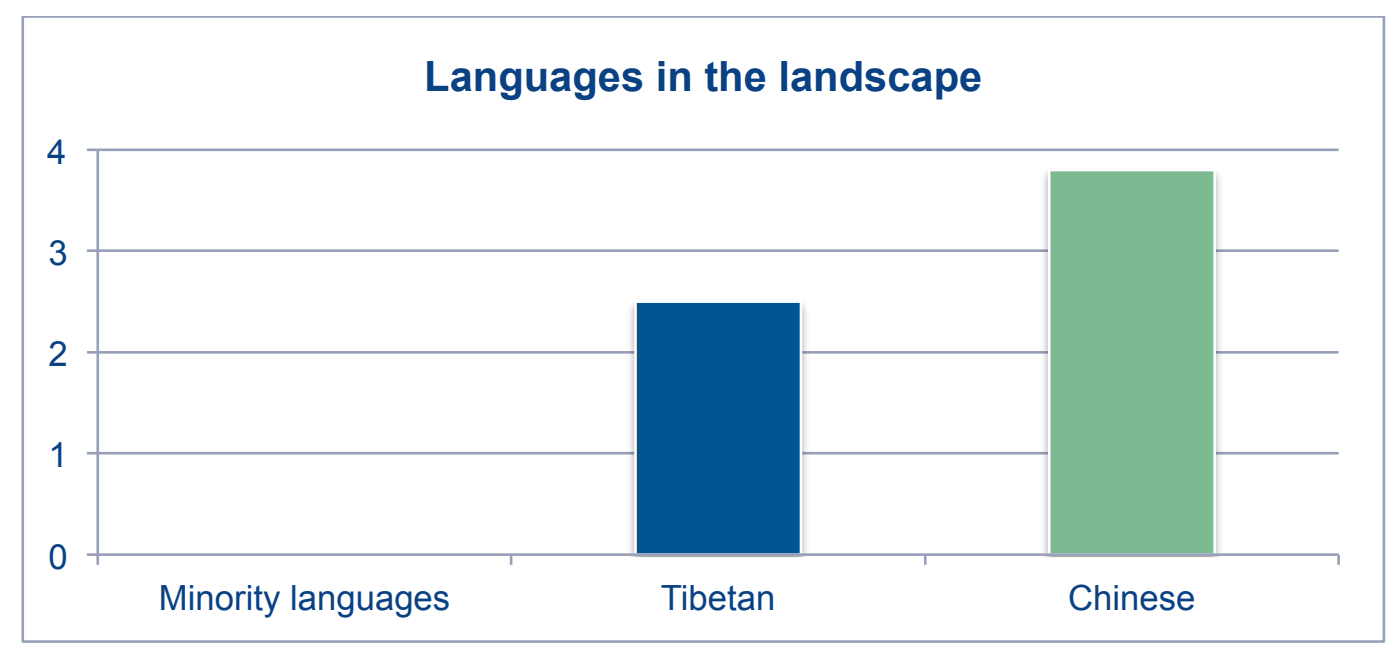

Chinese is more common in the linguistic landscape than Tibetan. None of Tibet's minority languages are visible in the linguistic landscape.

Figure 8. Responses to the question, "What language is dominant in these various forms of traditional and new media?"

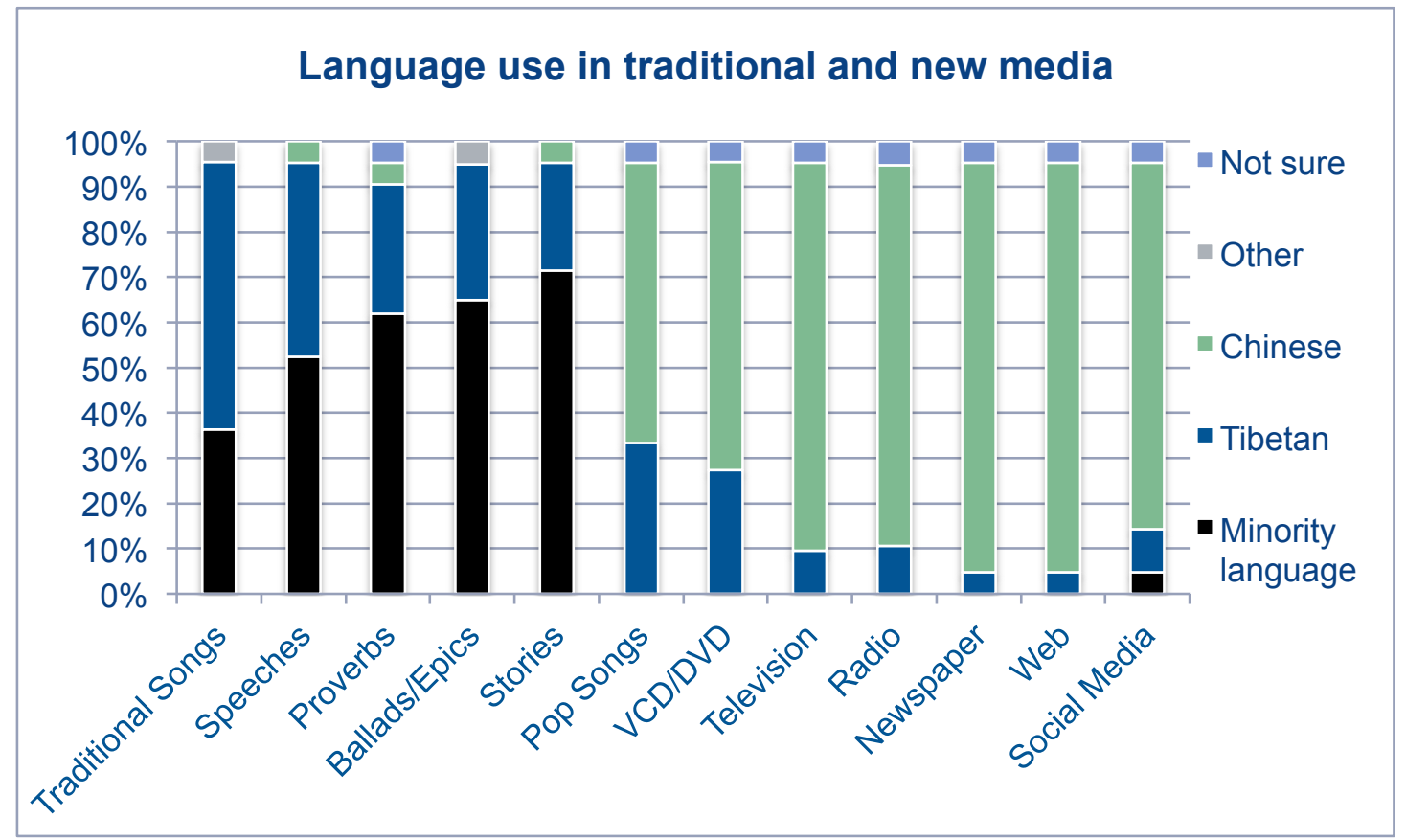

Minority languages and Tibetan dominate in traditional media, whereas Chinese dominates new media. 
Figure 9. Responses to the question, "What language is dominant in various levels of education?"

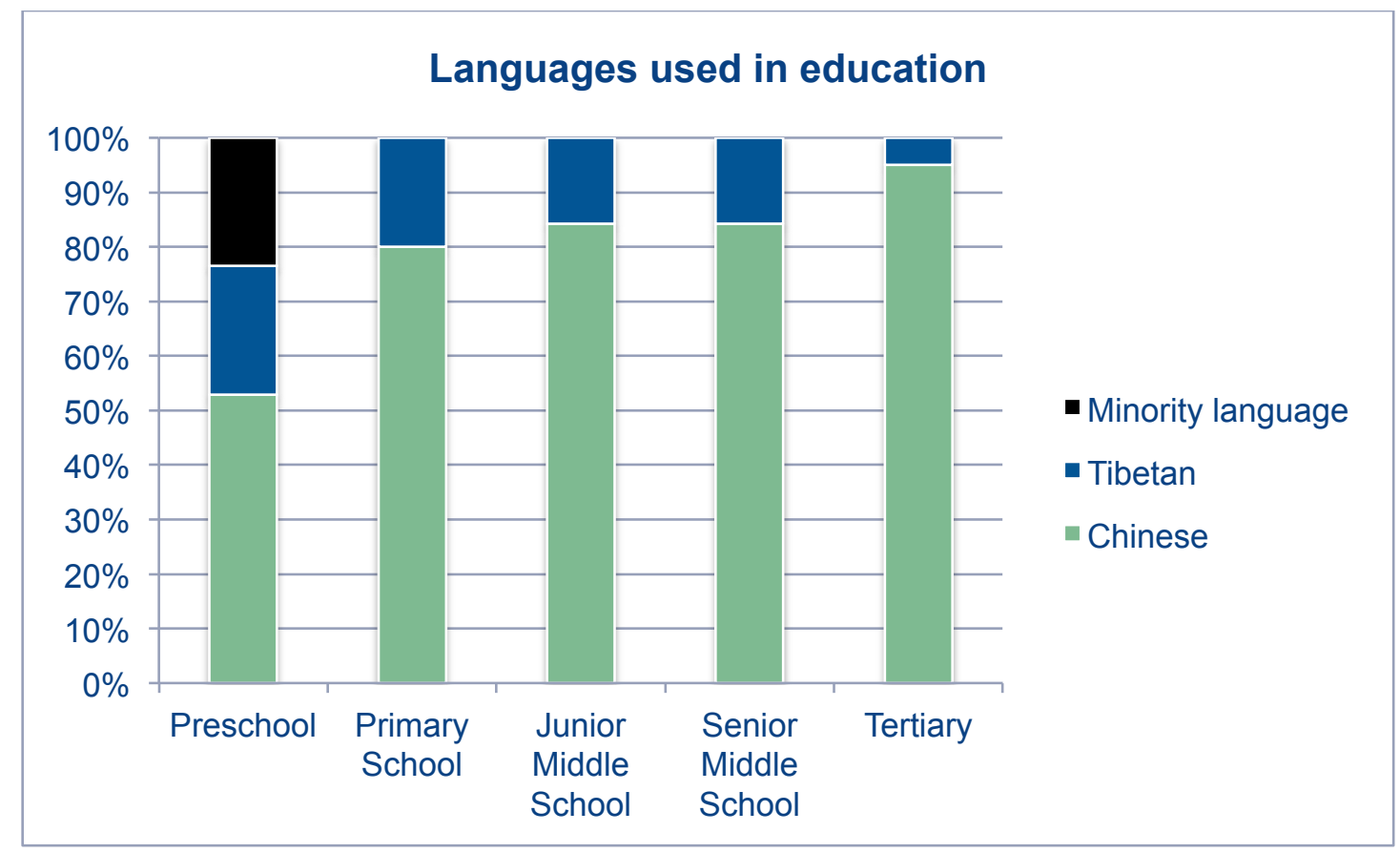

Chinese dominates at all levels of education, and Tibetan plays a decreasingly important role the higher one goes in the education system. Minority languages are only used in preschool education.

Figure 10. Responses to the question, "How are Tibetan texts used in religious practices?"

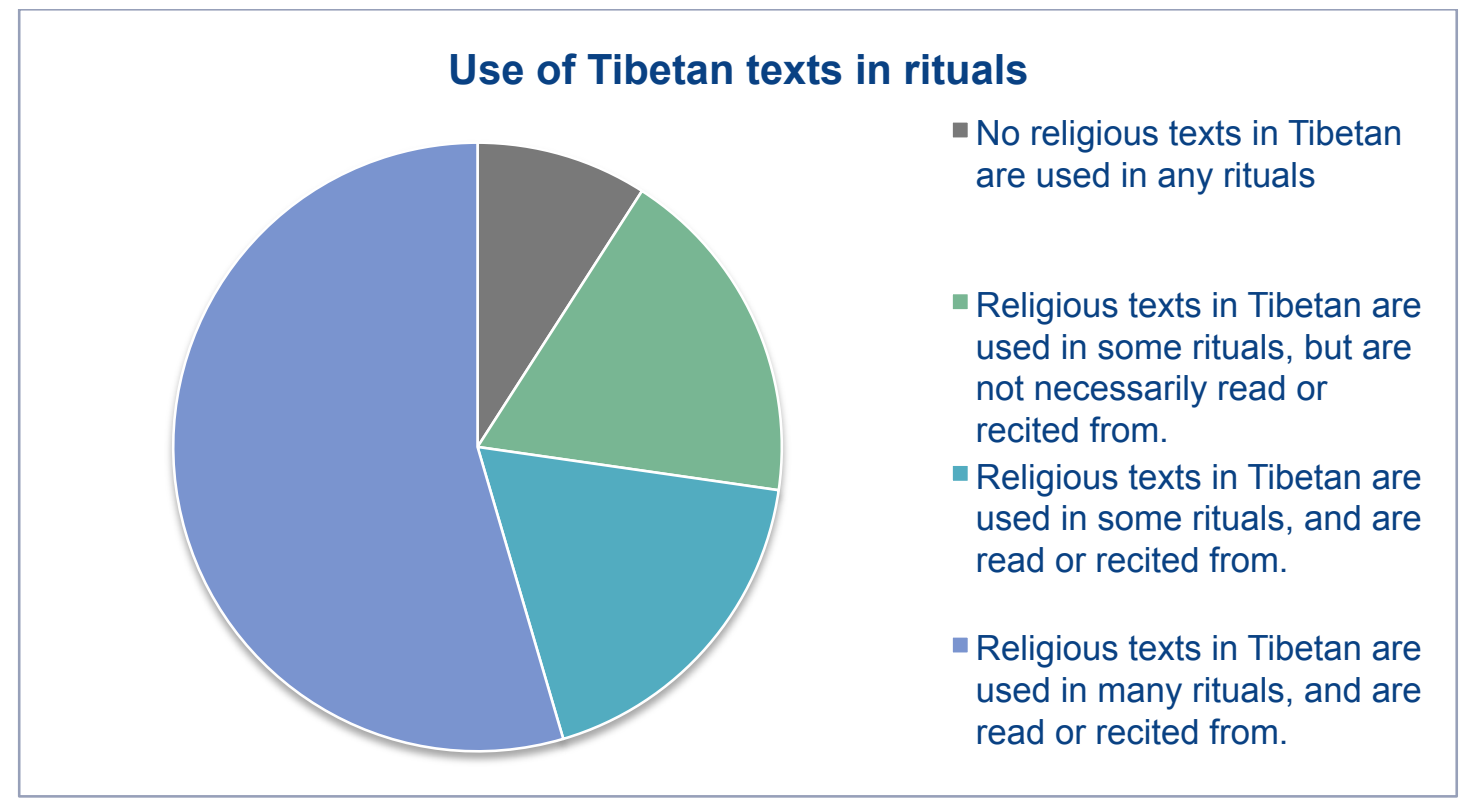

Although Tibetan texts are read from, there are also cases where Tibetans used texts primarily as props rather than documents, and also where no Tibetan texts are used at all. 
Figure 11. Responses to the question, "Which languages are spoken in religious practices?"

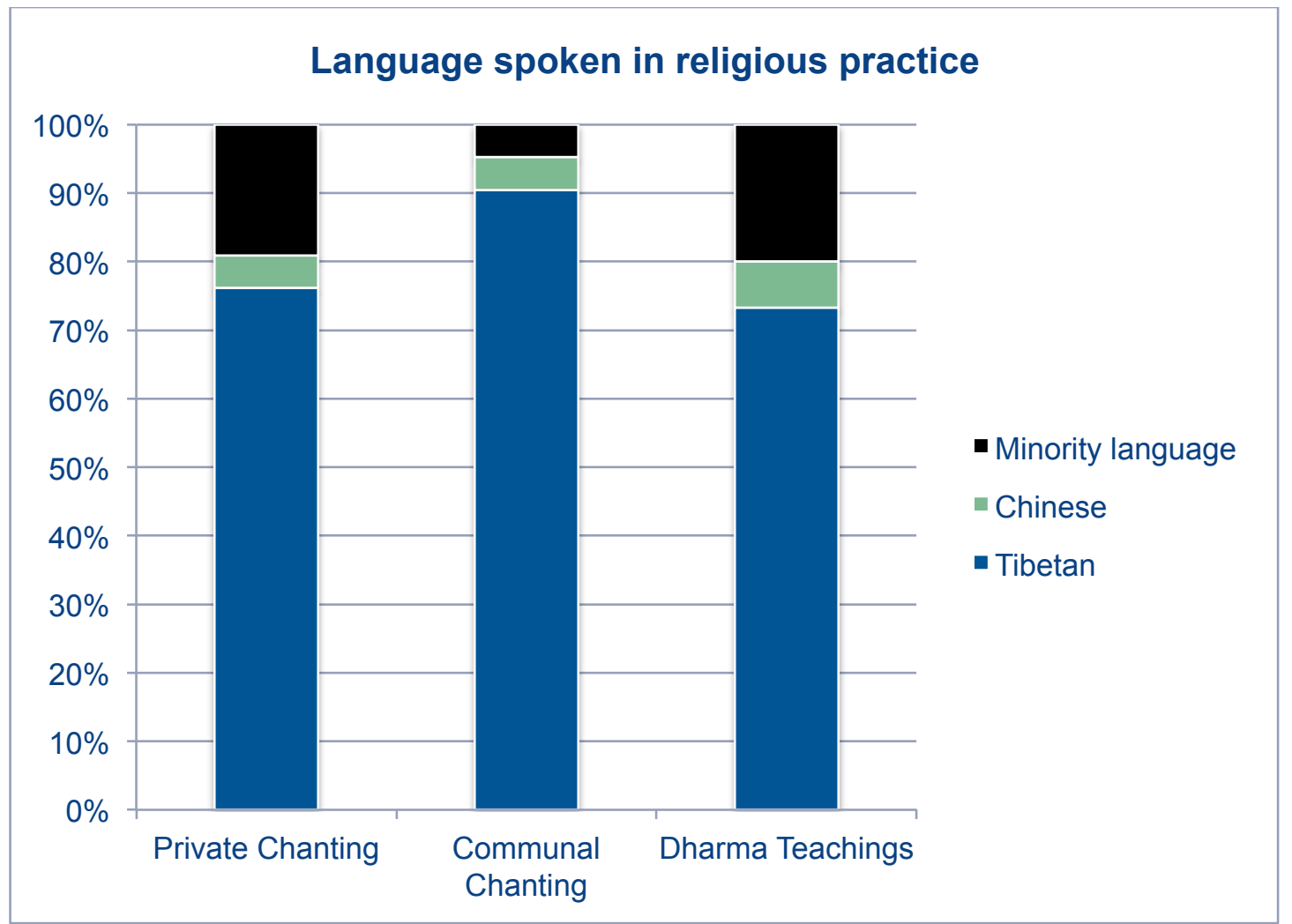

Tibetan is the most common language spoken in rituals, but minority languages play a role in private chanting and Dharma teachings. 


\section{Language Attitudes and Beliefs}

In addition to the broader social context, the survival of a language depends in part on what people think and feel about that language. First, let's look at how speakers of mainstream languages think about minority languages, and how they act towards their speakers.

Figure 12. Response to the question, "Are people ever laughed at or joked about for A) speaking their minority language, or B) speaking mainstream languages (Tibetan, Chinese) with an accent?"

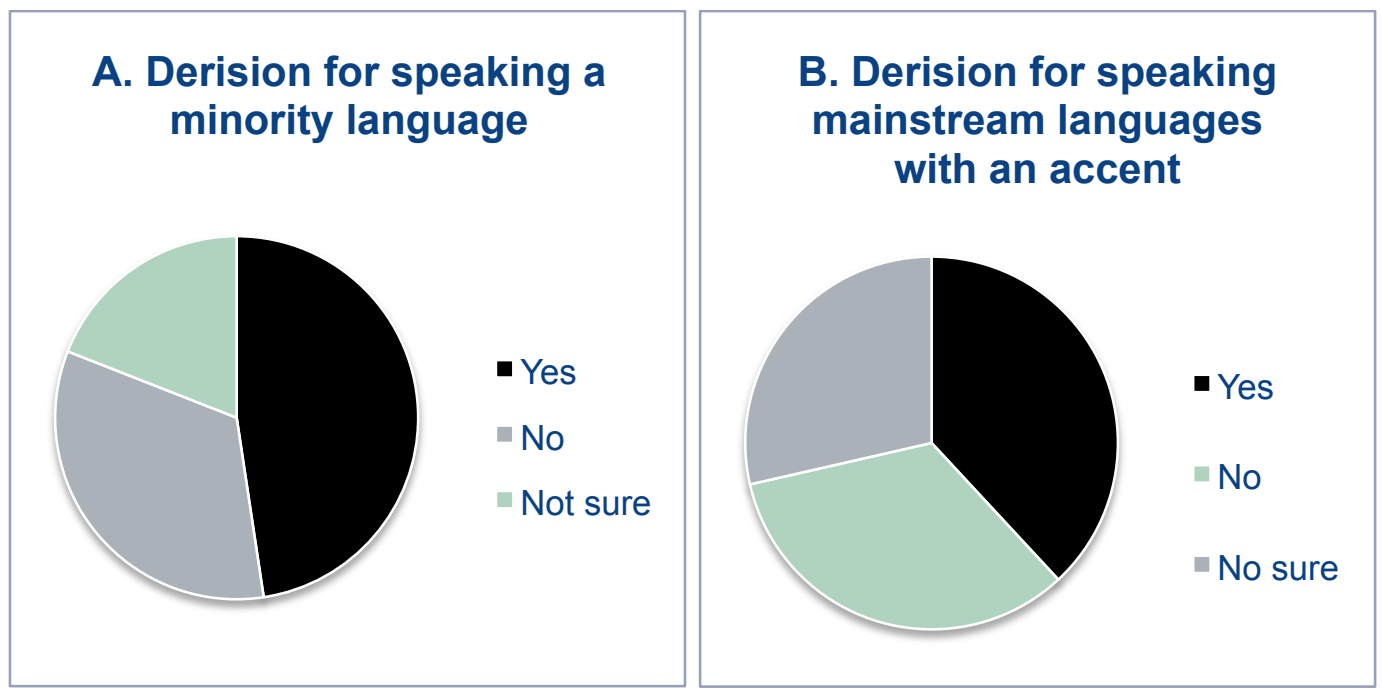

Derision is a relatively common form of linguistic discrimination. Nearly half (10/21) of the respondents report that people are laughed at for speaking their minority language. A further 7 could not be certain that this didn't happen. Meanwhile, only in 7 out of 21 cases were respondents confident that speakers were not derided for speaking mainstream languages with an accent.

Figure 13. Responses to the question, "A) Are people ever insulted, and B) Has physical violence ever occurred, in response to them speaking a minority language or speaking mainstream languages with an accent?"
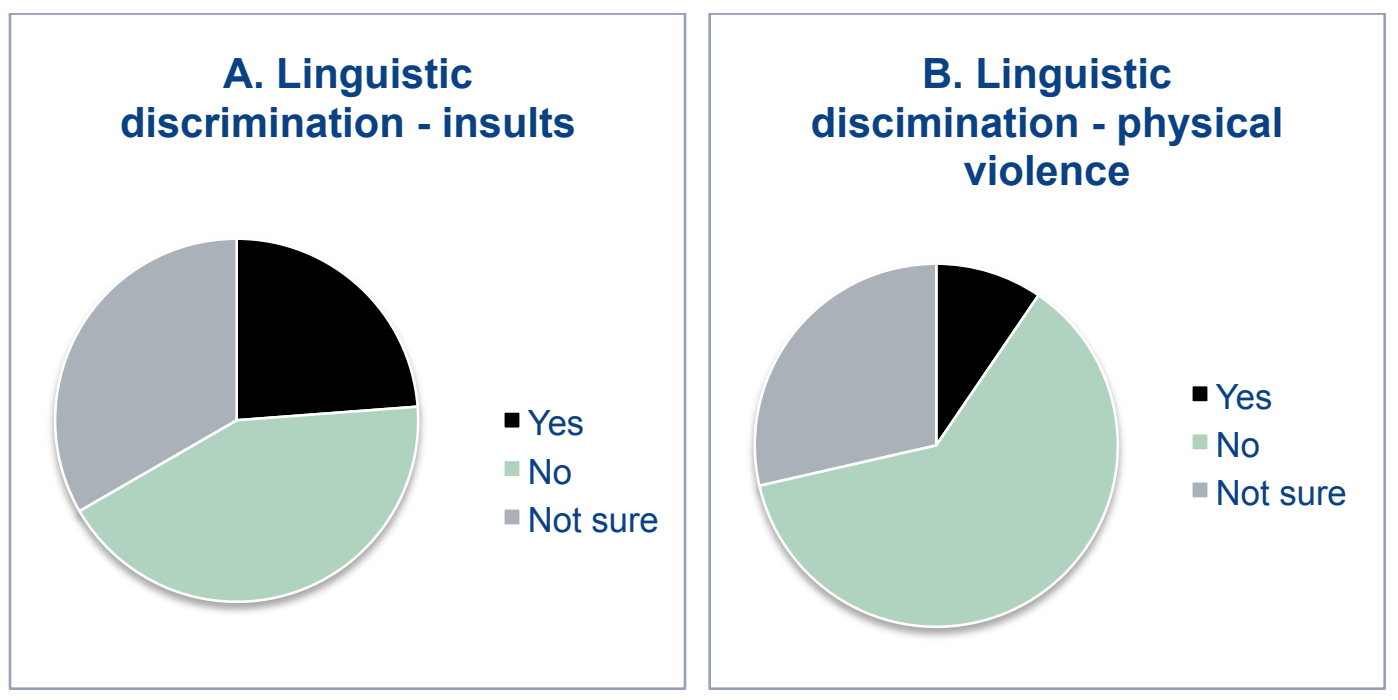

Insults and physical violence are less frequently encountered forms of linguistic discrimination, compared to derision (laughter and joking). However, it is worth nothing that for insults less than half of respondents $(9 / 21)$ could not rule out that some form of insults were used. It is only when looking at physical violence when a majority $(13 / 21)$ could be confident that no physical violence had targeted minority language speakers. 
Figure 14. Responses to the question, "How accurate are the following statements?" $(0=$ completely inaccurate; $1=$ somewhat inaccurate; $2=$ neither inaccurate nor accurate; $3=$ somewhat accurate; $4=$ completely accurate). All questions begin with, "Speakers of this language typically..."

...are worried about Chinese loanwords ...believe that language is learned automatically ...associate it with the past, ancestry, \& tradition ....are proud of their multilingualism ...consider it an important aspect of their ethnic ...consider it an important aspect of their identity ...consider it to be useful ...consider it to be beautiful ...feel positive about it ...wish to maintain it but do not ...wish to maintain it

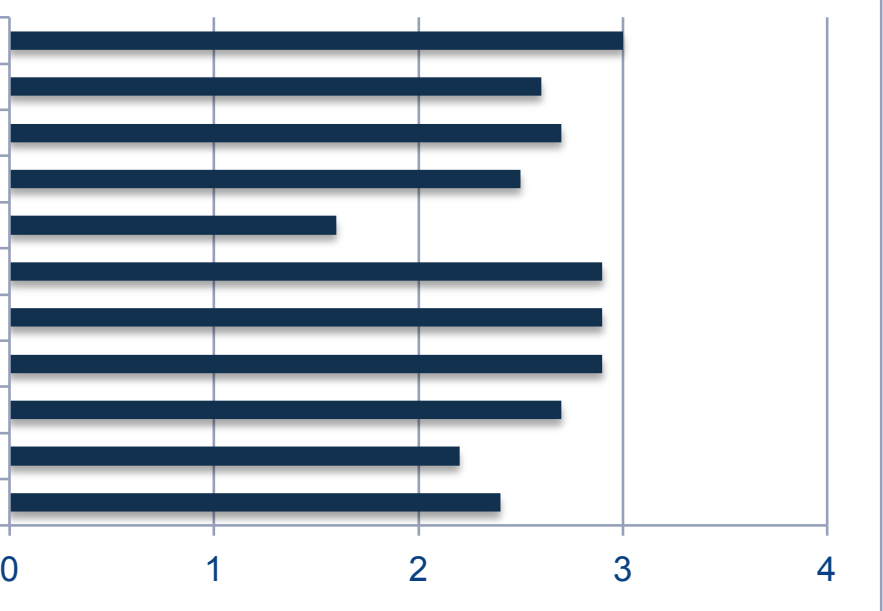

Two results stand out. First, it seems common that speakers of minority languages do not associate those languages with their ethnic identity, i.e., minority languages are not associated with Tibetan identity. A second thing to note is that it appears common for speakers of minority languages to be worried about the presence of Chinese loanwords in their languages. 


\section{Appendix One: The Languages}

Information was collected on the following languages. For further information about these languages, please consult the bibliographic resources available in the forthcoming article by Gerald Roche and Hiroyuki Suzuki, "Tibet's Minority Languages: Diversity and Endangerment," a draft of which is available here:

https://www.academia.edu/28138202/Tibets_Minority Languages Diversity and Endangerment.
1. Baima
2. Choyo
3. Ersu
4. Geshiza
5. Gochang
6. Heishui Rma
7. Henan Oirat
8. Khroskyabs
9. Lhagang Choyu
10. Lizu
11. Manegacha
12. Minyak
13. Namuyi
14. nDrapa
15. Prinmi
16. rTa'u
17. Shixing
18. Situ Rgyalrong
19. Tosu (Duoxu)
20. Zbu

These languages can be seen on the map below. 


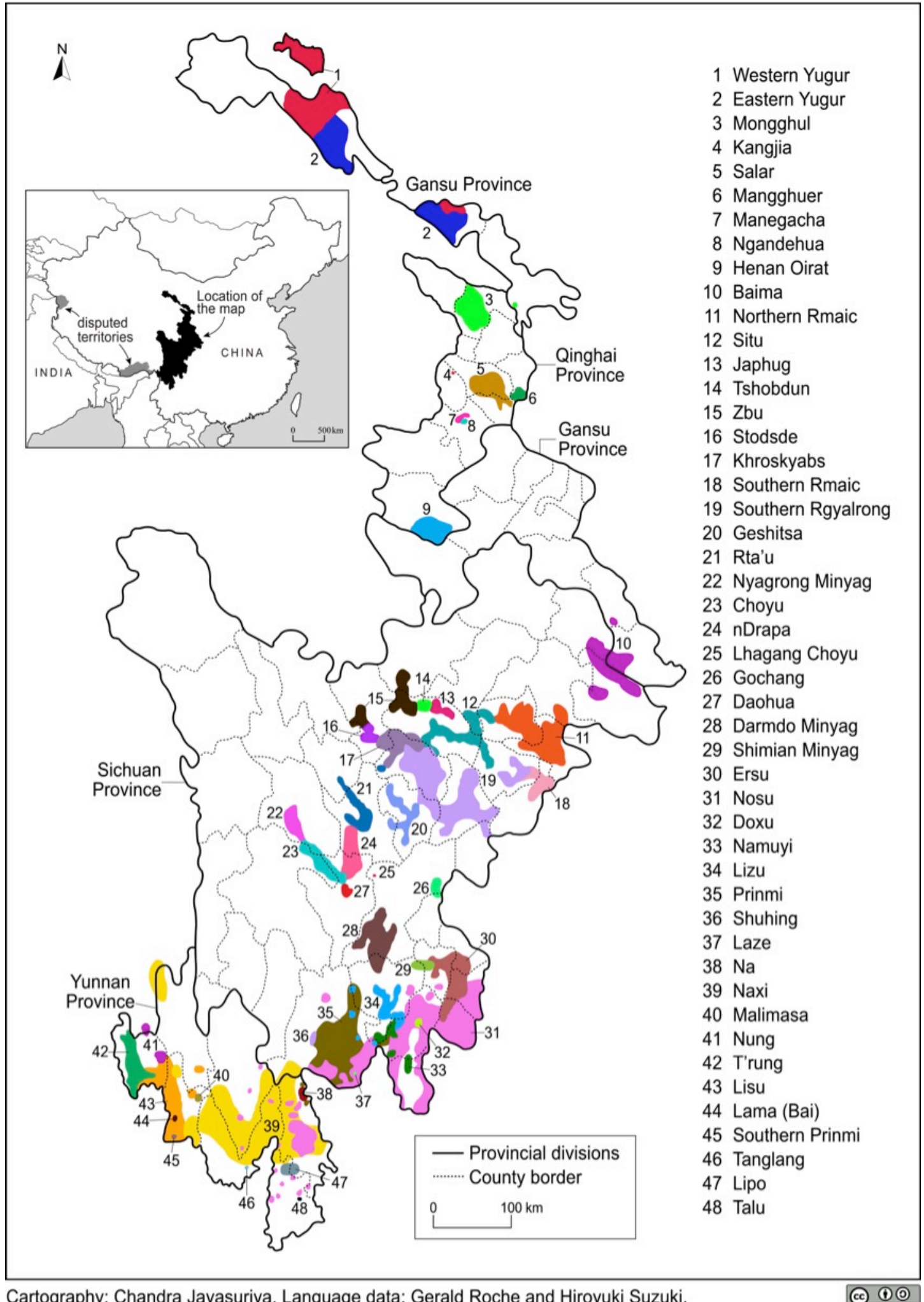




\section{Appendix Two: Participants}

Not all participants in the survey agreed to have their identity made public. Below is a list of participants who consented to having their details made public.

Elvis Yang Huang, Southwest Jiaotong University (China)

Franz Huber (Switzerland)

Fuminobu Nishida, Tohoku University (Japan)

Hiroyuki Suzuki, University of Oslo (Norway)

Katia Chirkova, CNRS-CRLAO (France)

Kristin Meier (Germany)

Lai Yunfan, Max-Planck Institute for the Science of Human History (Germany)

Mátyás Balogh, Elte University (Hungary)

Sami Honkasalo, University of Helsinki (Finland)

Satoko Shirai, Japan Society for the Promotion of Science/ University of Tsukuba (Japan)

Yina, University of Oregon (USA)

Zhang Shuya, INALCO-CNRS (France) 


\section{Appendix Three: Defining Vitality Status}

The different vitality statuses were classified as follows.

Extinct. Nobody speaks the language. There are no records of it.

Sleeping. The language is no longer spoken, but records of it exist.

Nearly extinct. Only a small number $(<10)$ people of the grandparent generation speak the language; no new speakers are learning it.

Moribund. Many people ( $>10)$ of the grandparent generation speak the language; no new speakers are learning it.

Highly endangered. All people of the grandparent generation speak the language; some people of the parent generation speak it.

Endangered. All people of the grandparent and parent generation speak the language. No children $(<18$ years old) speak the language.

Shifting (advanced). Most children do not speak the language.

Shifting (moderate). Some children do not speak the language.

Threatened. All or almost all children speak the language, but if current conditions continue, intergenerational transmission is likely to be interrupted in the near future.

Stable. All or almost all children speak the language and are likely to continue doing so in the near future. 


\section{Appendix Four: Mapping Language Shift}

Languages to the left of the red line are shifting to Tibetan; those to the right are shifting to Chinese.

Minority Languages of the Eastern Tibetosphere

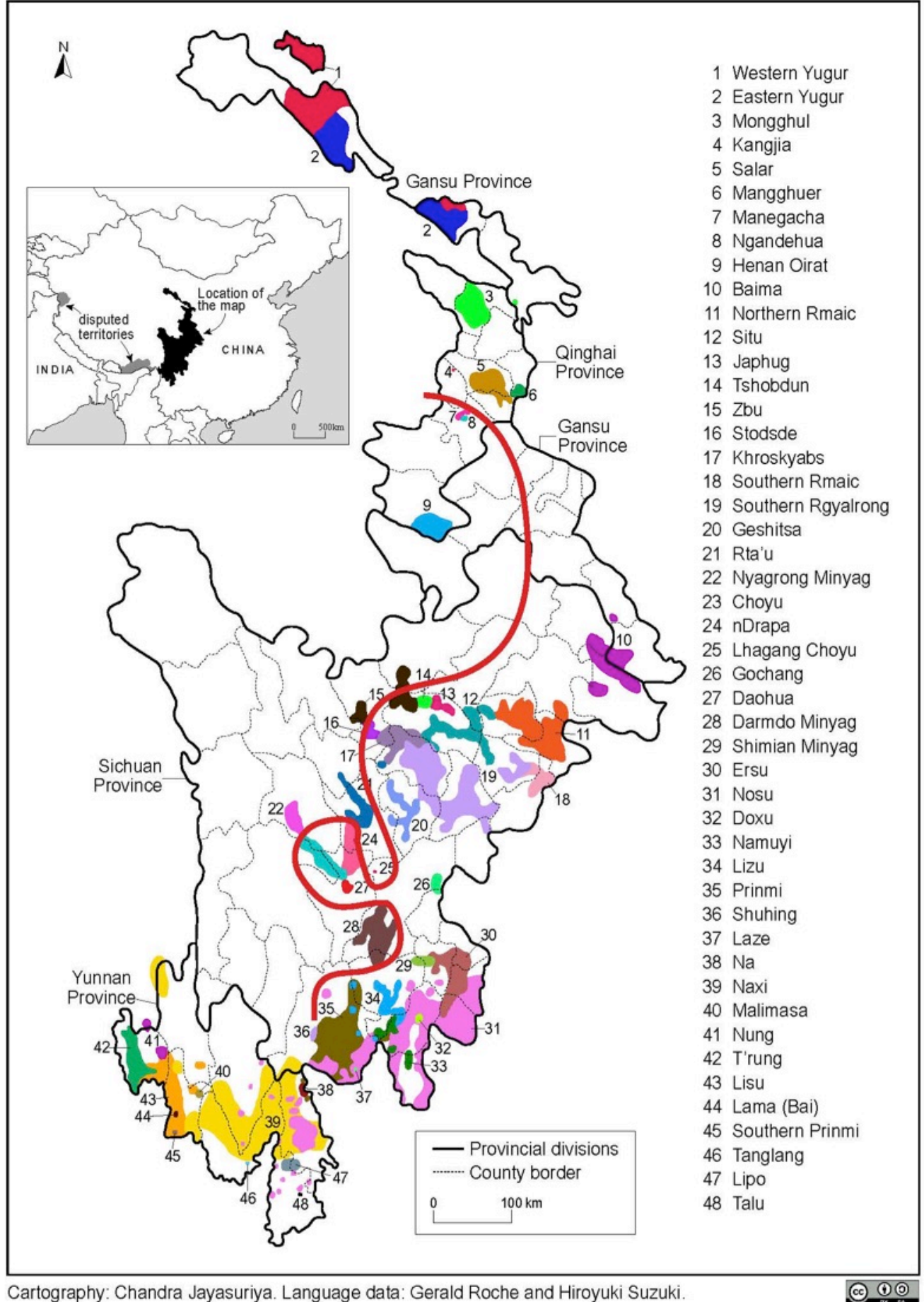

